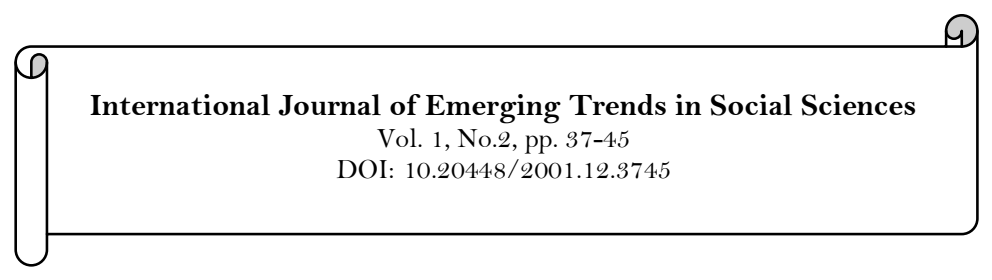

\title{
A Look at Semantic Issues in News Writing and Reporting
}

\author{
Godspower Udoh ${ }^{1}$ \\ Uwem Akpan' \\ Abasiama Peters ${ }^{3}$ \\ 1,2 Department of Communication Arts University of Uyo, Nigeria. \\ ${ }^{s}$ Department of Linguistics and Communication Studies University of Port Harcourt, Nigeria.
}

\begin{tabular}{|c|c|}
\hline Abstract & \\
\hline $\begin{array}{l}\text { The essence of news writing and reporting is communication - } \\
\text { sharing of meaning between the news writer or reporter and his } \\
\text { audience. With this fact in mind, it is expected that news be written } \\
\text { or reported such that the meaning intended by the news writer or } \\
\text { reporter is the meaning understood by the audience and nothing } \\
\text { more. However, due of a reporter's and, sometimes, editor's semantic } \\
\text { limitations, some commonly used news expressions are sometimes } \\
\text { applied out of context, thus creating certain semantic confusion. } \\
\text { Informed by these observed semantic discrepancies in some } \\
\text { newspapers and other news media in Nigeria, this article discusses } \\
\text { certain interrelated semantic issues and their influence on news } \\
\text { writing and reporting. The paper discusses what it calls semantic } \\
\text { confusion, identifying its possible causes. It also discusses some news } \\
\text { writing and reporting words and expressions (particularly verbs) } \\
\text { that are often misapplied by reporters and editors, thus adding to the } \\
\text { confusion. The article concludes that semantic knowledge remains } \\
\text { one of the one of the key requirements for better news writing and } \\
\text { reporting, especially in Nigeria where English is used not only as a } \\
\text { second language but as the major language of news dissemination. }\end{array}$ & $\begin{array}{l}\text { Licensed: } \\
\text { This work is licensed under a } \\
\text { Creative Commons Attribution } \\
\text { 4.0 License. } \\
\text { Publisher: } \\
\text { Scientific Publishing Institute }\end{array}$ \\
\hline
\end{tabular}

\section{Introduction}

As writers, journalists are, or are supposed to be, wordsmiths of a sort. This is because words of the language, through which journalists communicate, are journalists' basic articles of trade. In other words, journalists think primarily in action, pictorial, descriptive and simple words - verbs, nouns and adjectives using them commonly to put their messages across to readers, listeners and viewers. Besides listening, journalists watch people, places, situations and institutions, and then report or comment on their actions and inactions with the most appropriate words or expressions. With these and other lexical items, they make or create meanings in themselves and, later, in the minds of their audience. A journalist's romance with words plays itself out in a typical democratic setting where he parleys with politicians and tend to use words that will either please his political masters and/or displease others. This is done by creating appropriate meanings from such words. In the course of showcasing their word power, prowess and partnership, journalists (news writers and reporters in particular) use synonyms, antonyms, homonyms, homophones, and homographs as well as verbs as necessary and sometimes out of proportion. In fact there are cases where some newspaper editors, reporters, readers and other stakeholders with semantic curiosity often engage themselves in various forms of debates over the actual meaning of certain words used in a news headline and even in the body of a story. Sometimes, such debates result in court actions where those found guilty are given certain punishments. These, among other things, could be as result of the editor's or the reporter's poor attitude towards news words and their meanings. This scenario therefore underscores the need for those connected in one way or the other with the production of news, particularly in their textual form, to be more careful when it comes to word choice. It is important to add that apart from challenges associated with syntax, stylistics, and structure of news, young news writers and reporters are, today, faced with at general semantic challenges when it comes to news writing. A careful look at news reports, particularly, political news reports, in Nigerian newspapers, shows a preponderance of misapplied words and expressions. Some of these words and expressions, which are 
to be listed and explained later as an issue in this discourse, have become a source of worry. As already mentioned, some litigations arising from misrepresentations, outright libel or defamation, often arise from the providence of what a particular word or expression used in news and other media articles really means. This is where semantics comes in and a look at some of the preliminary challenges becomes necessary. The first challenge is the challenge of mother tongue.

Some news reporters, who use English as a second language, often turn out to be more prone to semantic confusion arising from their fascination for some sweet-sounding words or their commission of the thought process errors of a mother tongue which is transliterated to English. When news writers and reporters encounter a word in a passage more often than not, he may be tempted to give meaning to whatever is being conceived in the present. Hardly do writers today intend that words should mean what the ancients ascribed to them, especially when the words have changed in meaning. Thus, contrary to a reporter's mother tongue, certain English words, for instance, continually change their meanings. The second challenge is the challenge of etymology. Just as students frequently falter in their examinations simply because they were unable to interpret questions correctly or if they were able to do so, they were unable to put their thoughts correctly before their examinations; news writers and reporters sometimes present wrong reports because they could not know the original meaning of a particular word used by their sources. It must be pointed out that the origin of a particular word has a lot to do with the meaning of that word.

Knowing the contextual meaning of a word means knowing its origins, and its different possible meanings. Whereas one is not free to change the meaning of a word, one can, with care, extend its meaning. It also means one may know a word's correct shape, (spelling) sound (phonetics) and may also be aware of the relationship it shares with other words. Thus, as corroborated by Eyo (2005) every word in any language has certain semantic properties of class (parts of speech or function), shape (spelling), meaning (what it stands for or denotation) and what it implies (connotation), as well as the property of sound (phonetics).

In choosing words meant for writing, a reporter can be guided by the historical record contained in a good dictionary, but he cannot be bound by it, because new situations, new experiences, new inventions, new feelings usually compel a writer to give new uses to old words and this, at times, could cause confusion; hence the need to look at specific semantic confusion issues.

\subsection{Issue One}

\subsubsection{Semantic Confusion Issues and their Effects on News Writing and Reporting}

Issues, in this context, have to do with textual disorders which often impede meaning and thereby affect effective communication of news. They are discussed according to their sources and causes.

\section{Synonymic Confusion}

English language is very rich in synonyms. To Udoh (2014) this is partly because of the numerous borrowings which the language has made from other languages and which have in turn enriched it. These synonyms are usually sources of semantic confusion, in-exactitude and sloppy writing in the language and by extension in news writing and reporting. In communication, synonyms do not mean the same thing, and in most cases do not lend themselves to direct interchange in the usage in all contexts, even when the meanings are identical. Journalists, particularly, young writers of news, ought to know that the key factor often used to discriminate between words that are closely related in meaning is to examine their relative narrowness in application. Thus, two similar words may be differentiated from each other by the narrow implication of the meaning of the one and the wider sense of the other. According to Udoh (2014) intensity of meaning is another factor for differentiating two or more synonyms. For example, momentous, significant, weighty, important have different levels of intensity and one cannot be rightly used for the other in the different contexts in which they may be applied. Even though one may speak of a weighty issue or an important, a significant or a momentous issue, one cannot say that they mean or communicate the same thing at all times. The same is the case with words (verbs) like, advise, admonish, warn, and caution, which are frequently used in news writing and reporting. The three may be used interchangeably but that does not mean they are the same in meaning and an editor or reporter, who is not careful about their real meanings risks answering unnecessary questions when his story is published or aired. Further discriminations can be made on account of the emotional context of the words in addition to their explicit or more factual meanings. For example, information and propaganda are separated only by the emotional connotation of the word, propaganda. For the news writer or journalist generally, his problem with synonyms begins with the moment he does not want to use the same word twice in his sentence or paragraph. It begins when the news writer wants to exhibit his rich vocabulary, grammatical prowess, and bombastic slant. From his point of view he considers it appropriate, and of course, mastery of language, to switch from one symbol to another without a consideration for the reader or general audience who has to frequently adjust to these new symbols. In communication arts, and precisely for the purpose of sharing meaning as quickly as possible, there is nothing wrong with using the same word twice in a news sentence. The primary consideration should be to enhance effectiveness and, thus, improve communication rather than the rather weak stylistic consideration of elegant variation. Examples of 
synonyms that are frequently confusing to young and inexperienced news writers and reporters attached to a particular beat include the following:

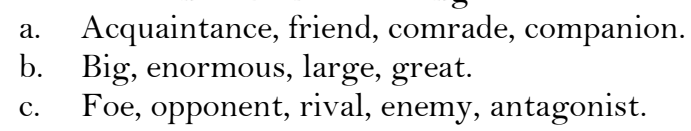

Words in each of the three groups are basically similar in meaning but they individually differ in their relative narrowness of application, intensity of meaning and emotional content. For instance, acquaintance, friend, comrade, and companion are similar in meaning but cannot be substituted in all cases. An acquaintance is not necessarily a friend; neither is a comrade a companion. Similarly, sport news writers and reporters should note for example, that, an opponent, as in sports, is not necessarily an enemy or foe. He may be a rival. The antagonist is very close to being an enemy and also a foe. The words, enormous, and big, may be similar in meaning, but a big man cannot also be described as an enormous or large man. In other words, both words cannot be used in the same context. To a politics reporter, a political opponent is not necessarily a political enemy, foe or antagonist. In the same vein, a political propaganda is not the same thing as information. Thus, care must be taken to ensure that words that do not have a similar intensity of meaning as the one to be replaced are not substituted unnecessarily in news meant for the masses. A dictionary of synonyms and thesaurus could be very useful in this regard. But the news writer must always bear in mind that there are no perfect synonyms since words generally have more than one meaning.

\section{Homophonic and Homonymic Confusion}

News writers and reporters using English Language should note that the language has a number of words which sound alike but which have different meanings and often, different spellings. These, unlike synonyms, create two problems: semantic confusion and spelling errors, which also affect meaning. The similarity in sound leads to another kind of confusion when the context is not definite. Also, this sameness in sound production may lead to another kind of problem which is associated with those with limited education. And if there are professionals that need proper education, journalists are a part of them. The homophones contained on this list, as also corroborated by Eyo (2005) are alphabetically arranged for easy reference. They are frequently used in news writing, and are combined with words which usually pose certain semantic as well as spelling problems. For a news writer or reporter to communicate well with the masses, each should be separately examined and used in such a way that there is no confusion in meaning even though they sound alike semantic doubts.

Advice/advise

Aid/aide

Aisle/isle

All ready/already

All right/ alright

All together/altogether

Altar/alter

Area/aria

Ascent/assent/accent

Auger/augur

Awhile/a while

Bail/ bale

Bare/bear

Belief/believe

Berth/ birth

Bolder/ boulder

Border/ boarder

Born/ borne

Brake/ break

Breach/breech

Breath/breathe/breadth

Bridal/bridle

Buy/by/bye

Cannon/canon

Canvas/canvass

Capital/capitol

Carat/caret/karat

Career/carrier

Cast/caste

Caster/castor 
Cease/seize/seas

Chafe/chaff

Chief/chef

Choose/chose

Chord/cord

Cite/site/sight

Clinch/clench

Cloth/clothe

Coarse/course/cause

Coma/comma/comer

Common sense/commonsense

Complacent/complaisant

Compliment/complement

Comptroller/controller

Consul/council/counsel

Corpse/corps/cops

Councillor/Councilor/counselor

Cruise/crews/Kruse/ cruse

Cue/queue

Damage/damages

Decease/disease

Decent/descent/dissent

Desert/dessert

Device/devise

Diary/dairy

Discreet/discrete

Dose/those

Draft/draught/drought

Dyeing/dying

Faint/feint

Fair/fare

Farther/further/father

Faze/phase/face

Fears/fierce

Fiancé/fiancée

Flack/flak

Flair/flare

Flier/flyer

Forbear/forebear

Foreword/forward

Forth/fourth

Foul/fowl

Funny/phoney

Genius/genus

Gin/gene

grill/grille

Hair/hare/heir

Hangar/hanger

Hat/heart/hart

Hear/here

Heard/head/herd

Hearse/hers

Heat/hit/heath

Hoard/horde

Hoarse/horse

Holy/holly/wholly

Hoping/hopping

Ice cream/ I scream

Idle/idol/ideal

Illicit/elicit

Incidents/incidence

Ingenious/ingenuous 
Instant/instance

Interment/internment

Its/it's

Know/no

Launch/lunch

Lead/led

Lessen/lesson

Liable/libel

Licence/lisense

Lightening/lighting

Literally/literary

Loose/lose

Magnet/magnate

Mail/male

Mantel/mantle

Maybe/may be

Miner/minor

Mite/might

Moral/morale

Motto/motor

Nave/naive

Of/off

Oneself/one's self

Our/hour

Passed/past

Peace/piece

Peace talk/pea stalk

Peak/peek/pique

Peal/peel

Peer/pier

Plain/plane

Pole/poll

Pore/pour

Practice/practise

Pray/prey

Premier/premiere

Principal/principle

Race/raise

Racket/racquet

Raise/raze

Rapped/wrapped

Rear/rare

Reek/wreak

reign/rein/rain

Recent/resent

Resin/raisin

Reason/risen

Rhyme/rime

Rite/right/write/Wright

Scene/seen

Sea/see

Serge/surge

Sew/so/sow

Shear/sheer/share

Shone/shown

Sick/seek

Sole/soul

Some/sum

Some time/sometime/sometimes

Sort/sot/sought

Stair/stare

Stationery/stationary 


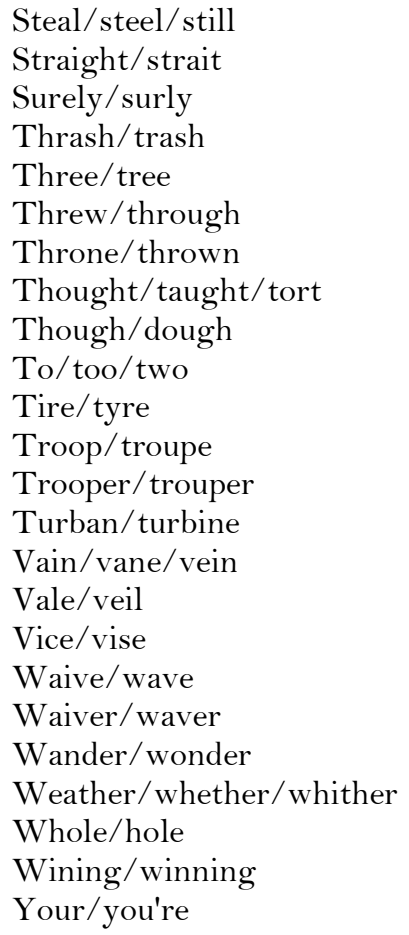

\section{Denotative and Connotative Confusion}

Denotation is used to refer to a thing in its strict nomenclature; a name given to something which refers to that thing alone. It is the first picture created in the mind about a word or expression. Denotation shows the explicit or primary meaning of a word, not its associations or implications. On the other hand, connotation is the meaning which a word acquires in addition to its original meaning. It is an associative meaning of a word, that is, that meaning which is implied representing a feeling, an emotion or value judgment. Thus, what a word denotes is its objective meaning, its specific, direct and explicit meaning while what it connotes are its acquired ideas and associations. A look at some common examples would make this explanation clearer. The word, "black", for instance, may simply denote the absence of light, a colour referent which can be readily identified by anyone who has been socialized in the language; whereas in its connotative sense, the word, black, may imply all kinds of pleasant and unpleasant associations, or suggestions which a culture attaches to it. In its pleasant sense, it can refer to a segment of the human race usually so-called, as 'in black man. It could also refer to the dirty, illicit, horrible, and malignant. It is therefore incumbent on news writers to take note that the connotative import of words elucidates the reporter's or writer's thoughts in many ways which may be more significant than the individual words as they may appear on paper. Another example is the word, home, which, primarily, refers to a place where one lives but may also have the connotative association of comfort and oneness of family (a pleasant association). For instance, (a) This is my home (meaning, this is where I live or hail from). (2) I feel at home here (meaning, I have some comfort here, which by extension explains one of the rolesof a home - provision of comfort and convenience etc). But it may at other times (though rare) suggest a deprived, cold environment (an unpleasant association). For example, hunter dogs abhor homes (meaning dogs trained for hunting do not like homes, which discomfort them). It is important for the news writer to note the different nuances of meaning which a word may have and ensure that he does not elicit such reactions as he may not have intended through the use of words which may turn out to have double edges. In order to avoid litigations and such other adverse reactions from the audience, a news writer should check against possible hidden suggestions which may not be apparent in some words. For instance, the words, thief, and suspect, do not convey the same meaning in news writing. A person is usually reported in the media as a thief if he is so declared by a law court; otherwise, he remains a suspect, even if he is arrested by the police. This semantic exactitude can be achieved by using a good, reputable dictionary even though such dictionaries are few; otherwise it is better to drop a word whose meaning is not clear to the news writer or reporter. However, if the writer is to depend on the dictionary, it should not be a dictionary that would define "good" simply as "that which is not bad" and would define "bad", as "that which is not good".

\subsubsection{Media-Related Semantic Confusion}

Obviously, the medium through which a news report is presented plays a significant role in clarity of meaning of the individual word used in the news report. In other words, the medium contributes to the semantic realisation of a particular news expression. In broadcast, the ability of the presenter or news reader to pronounce words correctly determines the ability of the listener or viewer to understand the meaning of the 
word. However, where a newscaster or reader does not pronounce a particular well, by way of misplaced stress, or poor accent, occasioned by many factors including mother tongue, there is bound to be semantic confusion. The observation in some of the modern broadcast media houses in Nigeria is that some of their presenters, announcers and news readers tend to adopt the American style of pronunciation of certain words, not minding the phonetic orientation of their audience. In Akwa Ibom State for instance, many of the newly established radio stations employ announcer who could have either been brought up in the West or just have a flair for Western phonetic realisation, hence the tendency to confuse listeners who are not in tune with such pronunciations. But this may not necessarily be a serious problem because broadcast news is largely spoken, which has little to do with spelling. This means that spelling contributes more when it comes to semantic confusion. In the case of print media, confusion usually arises in terms of spelling of words. A news writer's literacy level, in terms of correct spelling of words, adds a lot to the semantic realisation of such words. Some words are consistently spelt in different ways, depending on the linguistic orientation of the news writer. When this is mentioned, the popular American and British spelling patterns come to play. For example, words such as colour, favour, neighbour, honour, may become a source of confusion to an American oriented news reader who is used to color, favor, neighbor, and honor as the acceptable spellings to American users of the language. Whereas in broadcast news reporting (especially radio), such confusion rarely occurs, the confusion becomes more pronounced in print media news. This is because in print media, news expressions are seen with the eye; that is the audience sees the expressions lexically. He sees, smells, and even touches the spellings of the words used in communicating the news by the reporter. He is not only told; he sees the words, appreciates their spelling, before making meaning out of them.

\subsection{Issue Two}

\subsubsection{Frequently Misused Verbs in News Writing and their Tendency towards Semantic Confusion}

Udoh (2014); Wilber and Miller (2003); Bender, Davenport, Drager, and Fedler (2009) all agree that by reason of accuracy and sharing of meaning, which is the hallmark of communication, news should be written or reported in everyday language. Similarly, Udo (2015) stresses the need for writers to use the dictionary to know the different meanings attach to a particular word as failure to do this could result in confusion. This means that apart from grammar, the individual words used in communicating the news should be those that do not contain any semantic confusion; but rather should be the ones used by the greatest number of people in the society in which the media operate. Whether it is for print or broadcast media, news should be presented such that the meaning is understood by everyone (literate, semi-literate, educated and semi-educated) exposed to it. That being the case, news must be written in a language structure that does not only look simple and clear, but also in words whose meaning is precise. As earlier explained, what a word denotes is that word's primary meaning. A newspaper reader, radio listener, or television viewer is more interested in the denotative meaning of a word used in the news than its associated meaning. He would rarely ascribe any secondary meaning to a news symbol. One reason for this attitude is that news audiences are usually in transit, exposing themselves to news even when they are doing something else.

\subsection{Journalists and Verb Romance}

As mentioned earlier, journalists think mainly in verbs, and then in nouns and adjectives. Their heavy concentration with verbs arise from the fact that news stories that hit the front pages of newspapers are mainly news of people's actions, and verbs are the words used in expressing those actions. However, in news writing, there are action verbs that are used regularly, that is they are found repeatedly in many news stories. But often, even though such verbs are everyday in nature, some untrained or careless writers often use them in a manner that rob such words of their originality, thus confusing or misdirecting the audience. These everyday news verbs, which are frequently used in their past form, include: said, stated, disclosed, observed, remarked, maintained, added and explained. What do these verbs (mostly used in their past forms) really mean, and when can a news writer or reporter use them to create the intended meaning? Or are they supposed to be used anyhow without recourse to their real meanings? An explanation of these regularly used verbs (in italics) and some of their wrong usages as quoted from local newspapers will suffice. He said that...

This appears to be the most frequently used verb in news writing and reporting. It is very rare to see a news report (written or spoken) that does not contain this word. It is equally the safest verb to use in news writing when it comes to semantics. On the other hand, it is, to writers with limited vocabulary, one of the most frequently misapplied. According to the BBC English Dictionary, the word, say, means to utter a word. In the context of news writing, the word, said, simply means stating directly or indirectly what a news source uttered during an interview or at a news event in its ordinary sense. Usually what a speaker said is a normal or ordinary statement. Let us consider this example:

1. One of the eyewitnesses remarked that the fire started at 12 midnight. (Wrong)

2. One of the eyewitnesses said that the fire started at 12 midnight. (Right)

Hardly would any other verb be better for the above quoted example than the verb, said. This is because the time that the fire started is not very special; hence there is no need for a narrower verb such as "remarked 
or disclosed". Also, what the eyewitnesses said in this case hardly requires any direct interpretation or emphasis by the news writer or reporter. It may come as a direct quotation or indirect report. One thing about the verb is that it is ordinary in meaning - it does not explain the manner that the utterance was made. He disclosed that...

If the explanation given above about the word, said, is fully appreciated, then the word, disclosed, does not only also mean, said, but is specific about how the thing was said. This means what one says can be a disclosure and if so, the use of said, rather than disclosed, would not convey appropriate meaning.

In news writing, especially in developmental journalism, a news source naturally "discloses" what was either hidden, what was not expected, or may not have been known by majority of the people. In other words, a disclosure is either a surprise or a shocker. One may disclose a new achievement, a discovery, a strange happening, etc. It would, therefore, be semantically wrong for a news writer or reporter to use the word, said, in place of disclosed, while trying to report, for instance, on a government's new educational package for the citizenry. This is because such a government package is yet to be unveiled and if a source tells a reporter about the plan, he is disclosing it. E.g.:

1. The Governor said that his administration has procured 5000 text and notebooks to be used by all secondary students in the State. (Wrong)

2. The Governor disclosed that his administration has procured 5000 text and notebooks to be distributed to secondary students in the State. (Right)

He observed that...

According to the BBC English Dictionary, one makes an observation when one watches or looks at something attentively and makes a comment, report or by extension, a discovery. Sometimes such comments are made officially, as in a situation where the observation is made publicly, in the presence of the press and in front of a camera. A news source is said to have made an observation when expresses his feeling about what he sees. Sometimes, the observer becomes scientific by proving what he observes. Usually, the observer tells his feelings about what he observes and may in the process make recommendations. This means that an observation is usually personal to the observer and should be reported as such by the news reporter. E. g.:

1. The State Governor observed that the last recruitment exercise conducted by the immediate past administration in Akwa Ibom State was not properly carried out. (Wrong)

2. The State Governor observed that many of those recruited into the teaching service were those who did not have teaching qualification. (Right)

It should be noted that the governor, perhaps, made the observation after taking a look at the list and credentials of those given appointment papers by his predecessor. Another verb that could substitute observed, in this context could be the word, discovered.

The governor remarked that...

Again, the BBC English Dictionary sees a remark as casual comment made from a brief observation. From this, it can be understood that a remark is usually made impromptu, or made briefly and on the spot. In other words, remarks are usually brief and straight to the point. At meetings that may not be very formal, one hears of chairman's opening remarks, guest of honour's remarks, etc, which may not necessarily mean an address or speech. So, in news writing or reporting, a news source may be prompted by a reporter to make an on-the-spot remark, not necessarily an observation. In this case, the news source speaks or comments freely on what he sees or experiences. Using the example cited under "observed", the following expressions, taken from some local tabloids, explain further:

1. When asked about what government intends to do with those who will not be found to have entered the teaching service properly, the governor observed that the rules guiding appointment into public service is clear (Wrong).

2. When asked about what government intends to do with those who will not be found to have entered the teaching service properly, the governor remarked that the rules guiding appointment into public service is clear (Right).

\section{He maintained that...}

Both the Advanced Learners Dictionary of Current English and the BBC English Dictionary agree that the verb, maintain, means to continue a situation or course of action in an unchanging order. In relation to news writing and reporting, it means reporting what a source said as a follow-up position. It means what the source said after his previous statement is a confirmation or continuation of that previous statement. This clearly means that the verb, maintained, cannot be used in news writing and reporting if what is "maintained" is not a follow-up to a previous position of a source. E.g.

1. The President commended Nigerians for their prayers and promised to return to the country soon. He maintained that the country will take the fight against insurgency more seriously (Wrong) 
2. The President commended Nigerians for their prayers and promised to return to the country soon. He maintained that he was feeling better after it was confirmed that the entire country had set aside one day for a prayer session for him (right).

Whereas the first example as quoted from a local newspaper contained a follow-up sentence that says something different from the first; hence using the verb, maintained, wrongly; the second sentence has a neck that that clearly continues with the President's position on his commendation for those who pray for his quick recovery.

She added that...

Contemporary dictionaries agree that "to add" means to put something into, or join something with another thing. One thing stands out clearly in this view - joining something with another thing. This joining something (news sentence) with another thing (sentence) is what makes the verb, added, different from the already explained verb, maintained. In contrast to maintain, , a source maintains by saying what he had already said in a somewhat different way; while he adds by making a statement they does not necessarily have something to do with his previous statement or position. E. g.

1. The Governor said he will float a scholarship scheme that would cover pupils in private nursery schools in the State. He added that his interest is in nursery one. (Wrong).

2. The Governor said he will float a scholarship scheme that would cover pupils in private nursery schools in the State. He added that he would pay teachers' salary promptly. (Right).

Note should be taken that unlike sentence one and its second part, the second sentence of the second example, which is right, is simply an addition to what the source said in the first example.

He explained that...

It is also very common for news writers and reporters to use the verb, explained, in their stories. But are they using the word in the proper context? Dictionaries see the word, explain, to mean to give account of something with enough clarity and detail. It means to clarify the meaning of something. Except where context demands this, the word, explained should be used with care in news writing and reporting. What this means is that, a news source can only explain operational (technical, difficult and controversial) words, expressions or statements. In other words, a news sentence needs not explain what is already clear to the audience. E. g.

1. The Governor explained that he is ready to serve the people diligently and with the fear of God. (Wrong).

2. The governor, who said he will run a canopy government, explained that a canopy government is a government that distributes appointive positions to both the members and supporters of the ruling and opposition parties.

It should be noted that the governor did not explain anything when he, in the first sentence as quoted above, simply stated what he would do in his position. But in the second sentence, there is something to explain - the meaning of "canopy government".

\section{Conclusion}

This paper has taken a look at some semantic issues that are relevant in news writing and reporting, which are of importance to young news writers of today. This has become important in view of the noticeable increase in newspaper and allied media establishment in Nigeria. After identifying and explaining some common semantic confusion which are usually created by news writers and reporters, the paper has identified and explained some common words which are often misapplied by some newspaper and other media establishments, especially in Nigeria where English is used as a second language. Now, the question is: are Nigerian newspapers and other media doing anything to reduce this confusion? Are they using words that are apt in meaning? From observation, it is true that some Nigerian news stories, as revealed in random examples cited, are still using certain verbs inappropriately. It would therefore not be wrong to conclude that the more news writers and reporters take the issue of semantics seriously, the faster they will reduces cases of litigations arising from poor word usages; and the more communicative their news stories will be.

\section{References}

Bender, J., Davenport, L., Drager, M., \& Fedler, F. (2009). Reporting for the media. New York: Oxford Universitys Press. Eyo, L. (2005). Effective use of English. Uyo: Billy Printing and Publishing Company.

Udo, D. (2015). Perspectives on use of English. Uyo: Robertminders International Limited.

Udoh, G. (2014). Neres writing and aesthetics. Uyo: Cle-Prints Ventures Limited.

Wilber, R., \& Miller, R. (2003). \& Harcup, T. (2009). Journalism: Principles \& practices. New Delhi: Sage Publications India Pvt Ltd. 